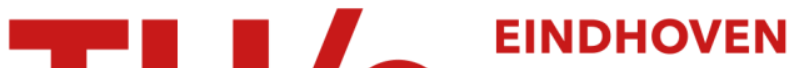

\section{Buffer capacity, ionic strength and heat dissipation in capillary electrophoresis}

Citation for published version (APA):

Reijenga, J. C., Verheggen, T. P. E. M., Martens, J. H. P. A., \& Everaerts, F. M. (1996). Buffer capacity, ionic strength and heat dissipation in capillary electrophoresis. Journal of Chromatography, A, 744(1-2), 147-153. https://doi.org/10.1016/0021-9673\%2896\%2900273-7, https://doi.org/10.1016/0021-9673(96)00273-7

DOI:

10.1016/0021-9673\%2896\%2900273-7

10.1016/0021-9673(96)00273-7

Document status and date:

Published: 01/01/1996

\section{Document Version:}

Publisher's PDF, also known as Version of Record (includes final page, issue and volume numbers)

\section{Please check the document version of this publication:}

- A submitted manuscript is the version of the article upon submission and before peer-review. There can be important differences between the submitted version and the official published version of record. People interested in the research are advised to contact the author for the final version of the publication, or visit the $\mathrm{DOI}$ to the publisher's website.

- The final author version and the galley proof are versions of the publication after peer review.

- The final published version features the final layout of the paper including the volume, issue and page numbers.

Link to publication

\section{General rights}

Copyright and moral rights for the publications made accessible in the public portal are retained by the authors and/or other copyright owners and it is a condition of accessing publications that users recognise and abide by the legal requirements associated with these rights.

- Users may download and print one copy of any publication from the public portal for the purpose of private study or research.

- You may not further distribute the material or use it for any profit-making activity or commercial gain

- You may freely distribute the URL identifying the publication in the public portal.

If the publication is distributed under the terms of Article 25fa of the Dutch Copyright Act, indicated by the "Taverne" license above, please follow below link for the End User Agreement:

www.tue.nl/taverne

Take down policy

If you believe that this document breaches copyright please contact us at:

openaccess@tue.nl

providing details and we will investigate your claim. 


\title{
Buffer capacity, ionic strength and heat dissipation in capillary electrophoresis
}

\author{
Jetse C. Reijenga*, Theo P.E.M. Verheggen, Johannes H.P.A. Martens, Frans M. Everaerts \\ Laboratory of Instrumental Analysis, Eindhoven University of Technology, P.O. Box 513, 5600 MB Eindhoven, Netherlands
}

\begin{abstract}
The composition of background electrolyte (BGE) in capillary electrophoresis (CE) is important for both selectivity and efficiency. Although the importance of $\mathrm{pH}$ and ionic strength predominates, attention should also be paid to specific conductivity, heat dissipation and buffering capacity. At a given $\mathrm{pH} /$ ionic strength combination, several buffers can in principle be used. Preference should be given to the so called Good type buffers because of the combination of higher buffering capacity and lower specific conductivity. Heat dissipation, leading to disturbances in migration and efficiency can thus be minimised. Buffer performance was calculated using a recently developed buffer selection and evaluation computer program.
\end{abstract}

Keywords: Buffer composition; Heat dissipation; Anions

\section{Introduction}

For the proper choice of background electrolytes (BGEs) in capillary electrophoresis (CE), aspects such as $\mathrm{pH}$, complexation and solvent effect are most important for selectivity purposes. Additional aspects such as buffering capacity, ionic strength, specific conductivity and heat dissipation deserve more attention in method CE development. The present contribution illustrates these effects.

Experimentally, it is not always practical, using a $\mathrm{pH}$ meter, to prepare a buffer with predetermined $\mathrm{pH}$ and ionic strength values. This is only the case if the buffer contains either a strong anion (e.g. chloride) or a strong cation (e.g. sodium). Only then is it possible, starting with a certain amount of $\mathrm{HCl}$ or $\mathrm{NaOH}$ respectively, to add base/acid to the desired $\mathrm{pH}$ and making up to the final volume, assuming buffering

${ }^{*}$ Corresponding author. capacity is sufficient in order for the $\mathrm{pH}$ to remain constant. Alternative ways of preparing buffers with a $\mathrm{pH}$ meter will lead to increasing ionic strength during preparation. When using most of the buffer constituents suggested in the present contribution, a desired $\mathrm{pH}$ and ionic strength can be obtained by preparation on a mass basis. Final slight $\mathrm{pH}$ adjustment using the $\mathrm{pH}$ meter will then not alter the ionic strength.

\section{Experimental}

Buffer performance was calculated using a recently developed buffer selection and evaluation computer programme CEBUFFER, intended for use with the HPCESIM simulation programme [1]. The programme uses a database of $\mathrm{p} K$ values and mobilities (at $25^{\circ} \mathrm{C}$ and infinite dilution) of ca. 300 components. The problem with the availability of these data is that whereas $\mathrm{p} K$ values of many components are tabu- 
lated, reliable mobility data are rare. Most of the data were taken from publications by Hirokawa et al. [2-4]. The buffer performance is calculated using the usual textbook equations. These are rather straightforward, as the $\mathrm{pH}$ and ionic strength are given, therefore all equilibrium concentrations can be calculated. What remains are two equations (the charge balance equation and the ionic strength equation) with two unknowns (the analytical concentration of both the anion and the cation). The output of the programme is presented as analytical concentrations in $\mathrm{mmol} / \mathrm{l}$, next to buffer capacity $(\mathrm{BC})$ and specific conductivity $(\kappa)$.

If there are more than two BGE constituents, say $n$, this approach does not work because then there are $n$ unknowns and only two equations and there are many combinations of the $n$ analytical concentrations that would lead to the same $\mathrm{pH} /$ ionic strength combination. In that case, $n-2$ of the analytical concentrations should be given in advance.

No corrections of mobilities at elevated temperatures were carried out. These would, on average, amount to ca. $2 \% /{ }^{\circ} \mathrm{C}$. In addition, $\mathrm{p} K$ values also depend on temperature, but these data were available only for a few components. Ionic strength correction of mobilities, however, was applied using a recently determined empirical relation [5].

\section{Results and discussion}

The composition of the BGE in electrophoresis is characterized by a large number of properties related to the performance of the analysis. The following aspects are not included in the present contribution; organic solvent modifiers, complex-forming agents, requirements regarding the BGE co-ion (UV absorbance, mobility matching) and additives to alter electroosmosis. What remains are $\mathrm{pH}$, ionic strength, specific conductivity and buffering capacity. Obviously these are interrelated. For the sake of clarity, they are first discussed separately. The first two (ionic strength and $\mathrm{pH}$ ) greatly affect selectivity and analysis time and should be course-tuned in initial optimization of selectivity. The last two (BC and $\kappa$ ) are essentially the result of the first.

\subsection{The effect of $p H$}

From elementary textbooks on CE it is obvious that for optimum resolution between weak sample ions, the BGE $\mathrm{pH}$ should be in the range of the corresponding $\mathrm{p} K$ values, unless the sample matrix is simple and separation according to differences in absolute mobilities is possible. A typical illustration is found by plotting effective mobilities vs. $\mathrm{pH}$ of the sample components to be separated (Fig. 1). In this three-component example, four different migration sequences are possible within one $\mathrm{pH}$ unit interval. In addition to resolution, the $\mathrm{pH}$ also dictates the specificity of the BGE; in terms of matrix interference, a low $\mathrm{pH}$ is favourable for anionic analysis (all anions are less mobile), whereas for cationic analysis, a high $\mathrm{pH}$ is preferred. There is an optimum in that respect because these conditions also lead to increased migration times. The practical $\mathrm{pH}$ range is limited roughly to between two and twelve. Outside this range, $\mathrm{H}^{+}$and $\mathrm{OH}^{-}$will predominate conductivity and inhibit buffering capacity.

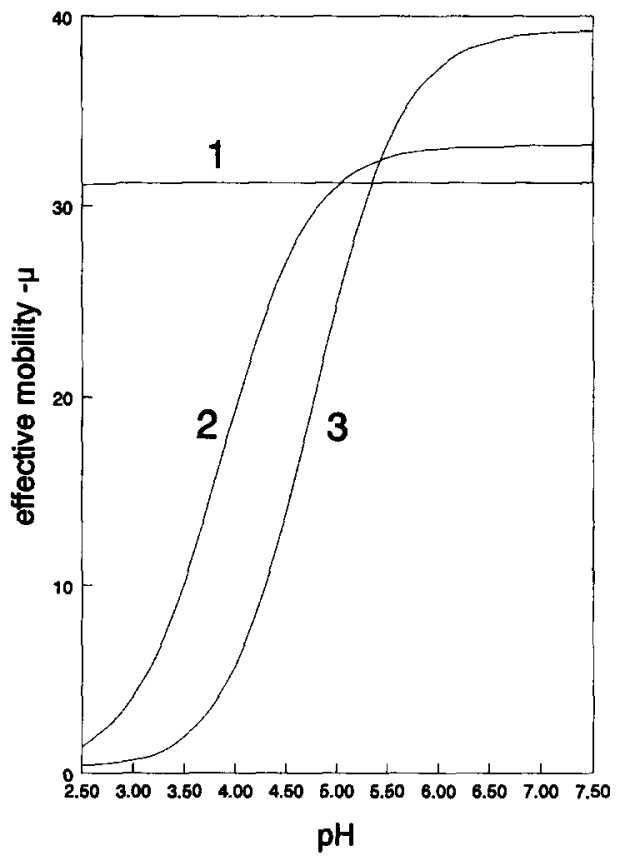

Fig. 1. The effect of $\mathrm{BGE} \mathrm{pH}$ on selectivity of monovalent ions at an ionic strength of $10 \mathrm{mmol} / 1.1=$ Naphthalene-2-sulphonic acid, $2=$ lactic acid, $3=$ acetic acid. 


\subsection{Ionic strength}

In order to make a buffering solution, ionic solutes should be dissolved, resulting in an inevitable ionic strength $I(\mathrm{~mol} / \mathrm{l})$, defined as:

$I=\frac{1}{2} \Sigma_{i}^{2} \cdot[i]$

where $z_{i}$ is the charge of the ionic species and $[i]$ is the equilibrium concentration $(\mathrm{mol} / \mathrm{l})$. Summation of Eq. I should be made over all BGE constituents.

Ionic strength, $I$, also has considerable influence on mobilities. As the dependence is more pronounced for multivalent ions, selectivity can be affected as well $[1,6]$. The following empirical relation was recently determined for a number of strong anions with charge numbers $1-6$ in the ionic strength range $1-100 \mathrm{mM}$ [5]:

$\mu_{i} / \mu_{i, 0}=\exp \left(-0.77 \sqrt{z_{i} I}\right)$

in which $\mu_{i}$ is the actual mobility, $\mu_{i, 0}$ is the absolute mobility, $z_{i}$ is the charge number of the solute and $I$ is the ionic strength of the solution.

Fig. 2. shows this effect of ionic strength on the actual mobilities of strong mono-, di- and trivalent anions. In the ionic strength range of interest in CE (between 5 and $50 \mathrm{mmol} / 1$ ), considerable mobility, and thus selectivity, differences are observed. In the example shown, four different migration sequences are possible, even in the relatively small BGE ionic strength interval. This implies that when reporting and comparing experimental results under different conditions, ionic strength can be as important as $\mathrm{pH}$. Reporting concentrations without stating the final ionic strength as well should be avoided.

\subsection{Specific conductivity}

The specific conductivity $\kappa(\mathrm{S} / \mathrm{m})$ of the BGE can be calculated with:

$\kappa=10^{3} \cdot F \cdot \Sigma \mu_{i}[i]$

in which $F$ is the Faraday constant $(96500 \mathrm{C} / \mathrm{mol})$.

As both specific conductivity, $\kappa$, and ionic strength, $I$, contain $\Sigma[i]$, increasing the concentration and thus the ionic strength of a certain buffer will

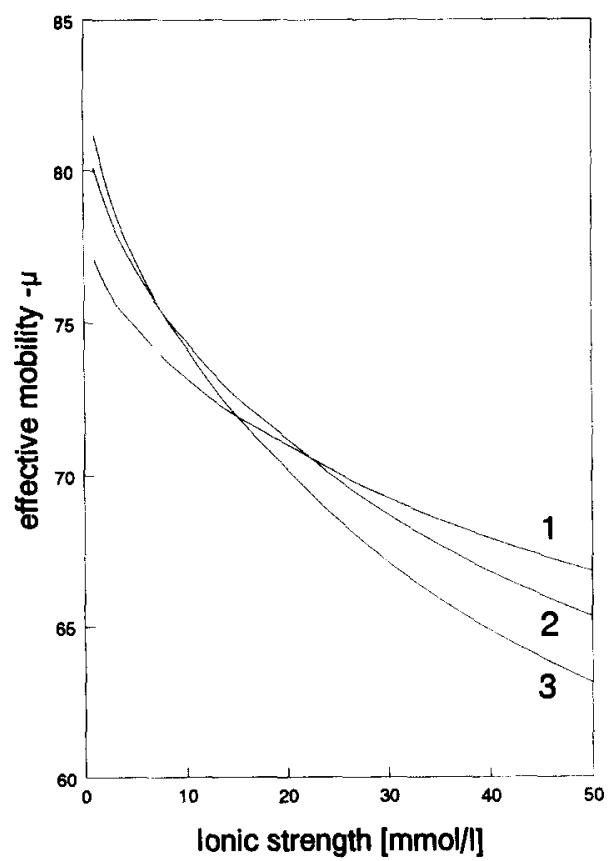

Fig. 2. The effect of BGE ionic strength, $I$, on the selectivity of strong multivalent anions at $\mathrm{pH} 8.00 .1=$ chloride, $2=$ sulphate, $3=1,2,3$-benzenetricarboxylate.

increase the specific conductivity as well. This increase is not by definition exactly proportional. Especially for multivalent buffers, ionic strength increases more strongly than specific conductivity.

\subsection{Heat dissipation}

Both specific conductivity, $\kappa$, and field strength, $E$, are responsible for heat dissipation. Heat dissipation in general is an unwanted side-effect in CE and is given by the following equation:

$P=j \cdot E=E^{2} \kappa$

in which $P$ is the heat dissipation $\left(\mathrm{W} / \mathrm{m}^{3}\right), j$ is the current density $\left(\mathrm{A} / \mathrm{m}^{2}\right)$ and $E$ is the field strength $(\mathrm{V} / \mathrm{m})$.

What we want is a voltage gradient, $E$, to turn mobilities into velocities. What we do not want is the current density that results in power dissipation. There are two consequences of this inevitable power dissipation. 


\subsection{Temperature rise}

The average temperature inside the capillary will rise, leading to mobility changes of $2-3 \% /{ }^{\circ} \mathrm{C}$. (Remember that $\mathrm{p} K$ values also change!). For example, in a $75-\mu \mathrm{m} \mathrm{I.D.} \mathrm{capillary} \mathrm{at} \mathrm{only} 30 \mathrm{kV} / \mathrm{m}$ and $10 \mu \mathrm{A}\left(j=2.3 \mathrm{kA} / \mathrm{m}^{2}\right)$, this amounts to $68 \mathrm{MW} / \mathrm{m}^{3}$, so that without heat transfer from the liquid, the temperature increase would be $16^{\circ} \mathrm{C} / \mathrm{s}$. If the capillary wall would absorb all heat without further dissipation into the environment, the temperature increase would still be larger than $1^{\circ} \mathrm{C} / \mathrm{s}$. This can be solved by efficient cooling of the whole capillary. Fig. 3. illustrates the striking difference between ideal forced liquid cooling and still air under commonly applied conditions. Any equipment will perform in between these two limiting cases. Note that with some equipment, not all parts of the capillary are thermostated in the same manner, so that longitudinal temperature differences are inevitable.

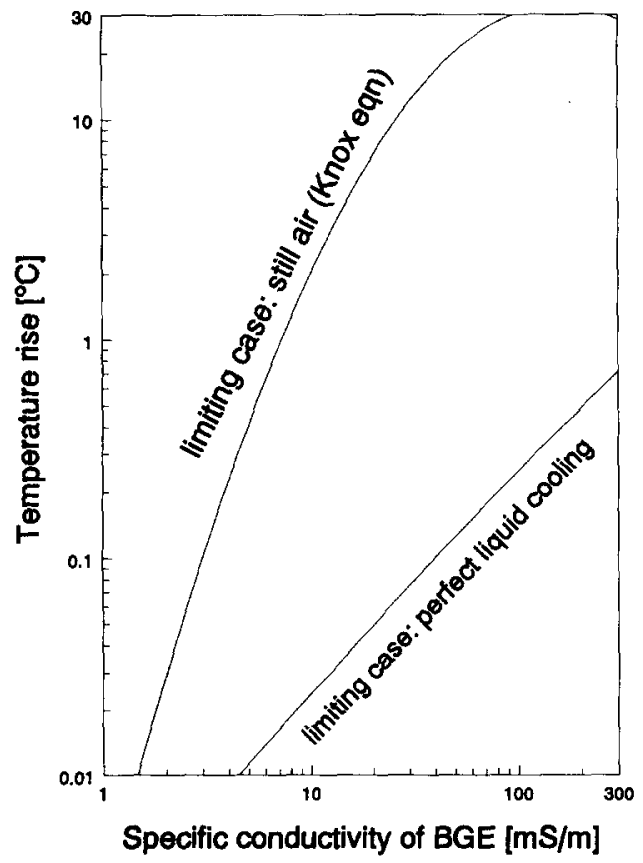

Fig. 3. The difference between ideal forced liquid cooling and still air under commonly used $\mathrm{CE}$ conditions. Average temperature rise in a $75 / 375 \mu \mathrm{m}$ fused-silica capillary at $50 \mathrm{kV} / \mathrm{m}$ as a function of $\mathrm{BGE} \kappa\left(\right.$ at $\left.25^{\circ} \mathrm{C}\right)$.

\subsection{Temperature gradient}

Radial temperature gradient in the capillary. This may lead to loss of plate numbers. The thermal plate height contribution [1] in a capillary, $H_{\text {ther }}$ is given by the equation:

$H_{\text {ther }}=\frac{f_{\mathrm{T}}^{2} \kappa^{2} E^{5} R_{\mathrm{i}}^{6} z_{i} F}{1536 R T \lambda_{\mathrm{s}}^{2}} \cdot f_{\mathrm{em}}$

where $f_{\mathrm{T}}$ is the relative temperature coefficient for mobility $\left(0.025 \mathrm{~K}^{-1}\right), R_{\mathrm{i}}$ is the inner diameter of the capillary $(\mathrm{m}), f_{\mathrm{em}}$ is the electromigration factor as the ratio of the effective and the apparent mobility [1], $\mathrm{R}$ is the gas constant $(8.3 \mathrm{~J} / \mathrm{mol} \mathrm{K}), T$ is the temperature and $\lambda_{\mathrm{s}}$ is the thermal conductivity of the solution $(0.6 \mathrm{~W} / \mathrm{m} \mathrm{K})$.

The proportionality to $R_{\mathrm{i}}^{6}$ indicates that miniaturization is favourable. In addition to that, only a lower power dissipation through $\kappa$ can solve this problem. If properly carried out, thermal dispersion seldom predominates under analytical, capillary conditions. Curiously enough, it is a widespread misunderstanding that cooling can further decrease this thermal dispersion, but this is not the case, as seen from Eq. 5 , the temperature is even in the denominator.

These two unwanted side-effects can be minimized by minimizing the specific conductivity, $\kappa$. In Fig. 4 , the specific conductivity is plotted vs. $\mathrm{pH}$ of a number of commonly used buffers (see Table 1) at the same, constant, ionic strength. What we observe is that the traditional sodium phosphate or borate buffers have a much higher specific conductivity than the so-called Good buffers [7]

\subsection{Buffer capacity}

In order to ensure that $\mathrm{CE}$ performance (migrational behaviour, efficiency) is as independent of the sample matrix as possible, the BGE should have sufficient BC. This is defined as the additional analytical concentration of strong acid/base needed for one single $\mathrm{pH}$ unit decrease/increase [8]. In determining $\mathrm{BC}$ with this definition, adding acid or base will almost certainly exceed the buffering range ( $\mathrm{p} K \pm 1$ ), so that the concentration of base necessary for a $\mathrm{pH}$ unit increase will not be the same as the 


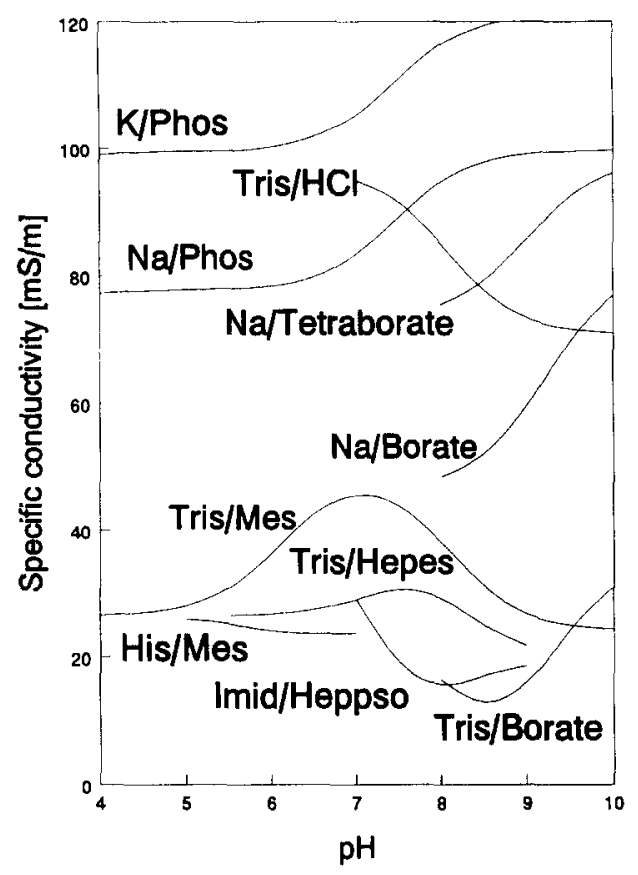

Fig. 4. Specific conductivity, $\kappa$, as a function of $\mathrm{pH}$ of a number of commonly used buffer combinations, at a constant $10 \mathrm{~m} M$ ionic strength.

concentration of acid necessary for the same decrease. For convenience therefore, $\mathrm{BC}$ is redefined as the differential concentration per $\mathrm{pH}$ unit:

$\mathrm{BC}=-\partial c_{\mathrm{HCl}} / \partial \mathrm{pH}=+\partial c_{\mathrm{NaOH}} / \partial \mathrm{pH}$

In the computer programme mentioned, the $\mathrm{pH}$ is changed over 0.001 unit and the concentration necessary to achieve this is calculated and multiplied by 1000 . In this way, both differential coefficients in Eq. 6 yield the same result.

The buffer capacity and the ionic strength are interrelated as well: For each BGE, increasing ionic strength will increase $\mathrm{BC}$ (for monovalent buffers around $\mathrm{pH} 5-9$, the relationship is approximately proportional). In Fig. 5, the BC of a number of BGEs is shown as a function of $\mathrm{pH}$, at the same ionic strength of $10 \mathrm{mmol} / \mathrm{l}$. In particular, sodium- and potassium-containing buffers are unfavourable, compared to Good-type double buffering systems. Special attention should be given to the Tris-2-(N-morpholino)ethanesulphonic acid (MES) system, which
Table 1

Suggested buffer components for $\mathrm{CE}$ on the basis of minimizing heat dissipation. Only the $\mathrm{p} K$ of interest is shown, $\mu$ values are at zero ionic strength. $25^{\circ} \mathrm{C}$, in $10^{-9} \mathrm{~m}^{2} / \mathrm{V}$ s units

\begin{tabular}{lcl}
\hline & $\mathrm{p} K_{\mathrm{I}}$ & $\mu_{\text {I }}$ \\
\hline Anions & & \\
Phosphoric acid & 2.12 & -35.10 \\
Trichlorolactate & 2.35 & -34.20 \\
Citric acid & 3.13 & -28.70 \\
Lactic acid & 3.85 & -35.80 \\
Hydroxyisobutyric acid & 3.97 & -33.50 \\
Tetraboric acid & 4.00 & -30.00 (estimated) \\
Glutamic acid & 4.38 & -28.90 \\
Acetic acid & 4.76 & -42.40 \\
Propionic acid & 4.78 & -36.90 \\
MES & 6.13 & -26.80 \\
MOPSO & 6.79 & -23.80 \\
ACES & 6.84 & -31.30 \\
BES & 7.16 & -24.00 \\
HEPES & 7.51 & -21.80 \\
HEPPSO & 7.99 & -22.00 \\
Boric acid & 9.23 & -40.00 (estimated) \\
Histidine & 9.34 & -28.80 \\
Alanine & 9.86 & -32.70 \\
$\beta$-Alanine & 10.24 & -30.80 \\
Cations & & \\
Aspartic acid & & \\
$\beta$-Ala & 1.99 & +31.60 \\
$\epsilon$-aminocaproic acid & 3.55 & +36.70 \\
Creatinine & 4.37 & +28.80 \\
Histidine & 4.89 & +33.10 \\
Imidazole & 6.04 & +29.60 \\
Tris & 7.15 & +52.00 \\
Ammediol & 8.08 & +29.50 \\
\hline & 8.78 & +29.50 \\
\hline
\end{tabular}

has a buffering range as wide as $\mathrm{pH} 5-10$ and is superior to all inorganic buffers.

\subsection{Peak symmetry}

Although not the subject of the present contribution, concentration overload will influence the choice of buffer as well and can seldom be neglected. This puts obvious additional constraints on the chosen buffer. In general, to get symmetric peaks, the co-ion mobility should be matched to the mobility of the sample ion of interest. For relatively fast sample ions, Good-type co-ions will lead to more skewed peaks than inorganic ions such as potassium, chloride and phosphate. Alternatively, Good-type co- 


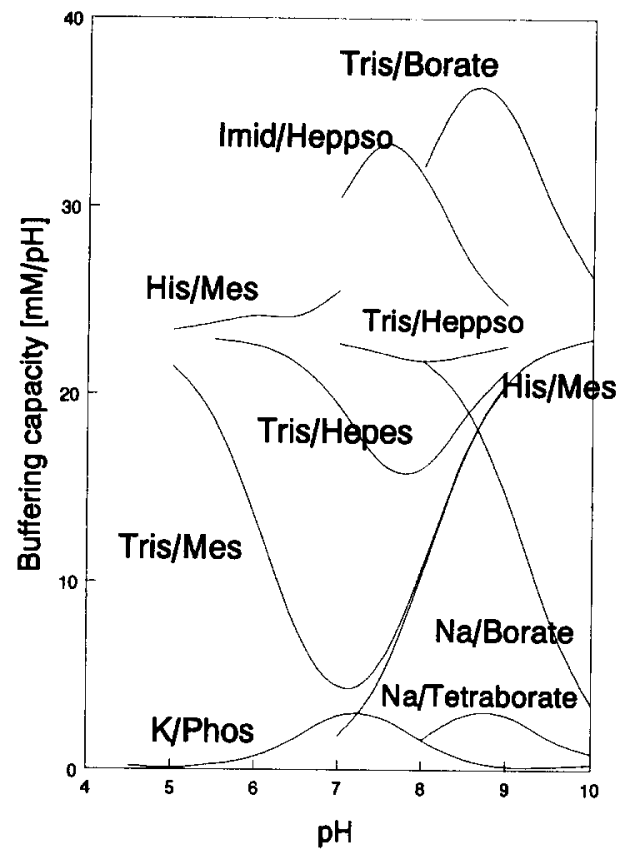

Fig. 5. The differential buffering capacity, $\mathrm{BC}$, of a number of BGEs as a function of $\mathrm{pH}$ at a constant $10 \mathrm{mmol} / \mathrm{l}$ ionic strength.

ions, at properly chosen $\mathrm{pH}$ values, will naturally give better mobility matching with sample ions with low effective mobility. In cases where the signal-tonoise ratios are unfavourable, co-ion mobility tuning may therefore have a higher priority than some of the other aspects highlighted in the previous sections.

\section{Conclusions}

The above results can be summarized by stating that, at a given $\mathrm{pH}$ and ionic strength necessary for selectivity, preference should be given to BGEs with a high buffering capacity and a low specific conductivity. If a plot is made of specific conductivity as a function of buffering capacity, then the lower right-hand corner is favourable and the upper lefthand corner should be avoided. This is essentially illustrated in Fig. 6 for BGEs in different pH ranges, but with the same ionic strength of $10 \mathrm{mM}$. Traditional buffers, e.g. on the basis of different sodium phosphate, borate and tetraborate salts, are clearly unfavourable, both in terms of $\kappa$ but also with regard to $\mathrm{BC}$ (Numbers 1-6). In most $\mathrm{pH}$ ranges, it is

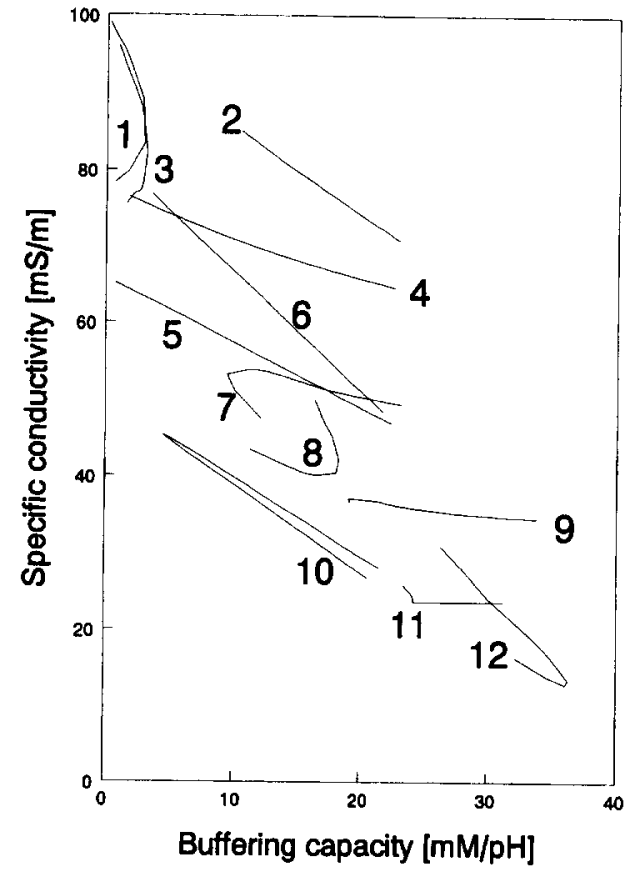

Fig. 6. Specific conductivity, $\kappa$, as a function of buffering capacity, BC, for different BGEs of $10 \mathrm{mmol} / \mathrm{l}$ ionic strength in different $\mathrm{pH}$ ranges: $1=$ sodium - phosphate $(\mathrm{pH} \mathrm{6-9)}, 2=$ Trischloride $(8-10), 3=$ sodium-tetraborate $(8-10), 4=$ sodiumphosphate $(2.25-3.5), 5=$ sodium-HEPES $(6-9), 6=$ sodium-borate $(8-10), 7=\beta$-Ala-phosphate $(2.25-3.5), 8=$ Tris-tetraborate $(8-10), 9=\beta$-Ala-citrate $(2.25-3.5), \quad 10=$ Tris-MES $(5-10)$, $11=$ His-MES $(5-7.25)$ and $12=$ Tris-borate $(8-10)$.

possible to choose buffers with both low $\kappa$ and high BC (Numbers 9-12).

Most curves, especially those of single buffering monovalent BGEs, such as sodium or chloride salts (Numbers 2, 4, 5 and 6) show continuous behaviour. Others show more or less irregular behaviour, with minimum or maximum values of either $\kappa$ or BC or both. This can readily be explained by minimum or maximum values in the $\kappa$ vs. $\mathrm{pH}$ or $\mathrm{BC}$ vs. pH plots (such as Figs. 4 and 5), which in turn originate from the fact that these plots were constructed at constant ionic strength.

Should a higher buffering capacity of a certain BGE be desired, then this can only be achieved by increasing the analytical concentration, whereby $\kappa$ increases as well. Both $\kappa$ and $\mathrm{BC}$ will increase approximately proportionally with analytical concentration.

Many of the traditional buffers, common in wet 
chemistry and HPLC, based on e.g. phosphate salts, should be replaced by organic, Good-type buffers, in order to improve CE performance. From a review of $300 \mathrm{CE}$ applications during 1982-1992, published in one of the textbooks [9], it was found that in 120 of them, phosphate buffers were used. In more than 80 applications, phosphate buffers were even employed in a $\mathrm{pH}$ range of between 4 and 11 . In view of the material presented above, it should be concluded that in choosing BGE compositions, more attention should be paid to the factors indicated in the present contribution.

The CEBUFFER programme is available from the author free of charge at the INTERNET address: TGTEJR@CHEM.TUE.NL.

\section{References}

[1] J.C. Reijenga and E. Kenndler, J. Chromatogr. A, 659 (1994) 403
[2] T. Hirokawa, M. Nishino and Y. Kiso, J. Chromatogr., 252 (1982) 49

[3] T. Hirokawa, M. Nishino, N. Aoki, Y. Kiso, Y. Sawamoto, T. Yagi and J.-I. Akiyama, J. Chromatogr., 271 (1982) DI.

[4] T. Hirokawa, Y. Kiso, B. Gas, I. Zuskova and J. Vacik, J. Chromatogr., 628 (1993) 283.

[5] W. Friedl, J.C. Reijenga and E. Kenndler, J. Chromatogr. A, 709 (1995) 163.

[6] J.C. Reijenga and E. Kenndler, J. Chromatogr. A, 659 (1994) 417.

[7] N.E. Good, G.D. Winget, W. Winter, T.N. Connoly, S. Izawa and R.M.M. Singh, Biochemistry, 5 (1966) 467.

[8] D.A. Skoog, D.M. West and F.J. Holler, Fundamentals of Analytical Chemistry, Saunders College Publishing, Orlando, $6^{\text {th }}$ Ed., 1992, p. 224.

[9] S.F.Y. Li, Capillary Electrophoresis--Principles, Practice and Applications (Journal of Chromatography Library, Vol. 52), Elsevier, Amsterdam, 1992 